\title{
ALA and ALA hexyl ester induction of porphyrins after their systemic administration to tumour bearing mice
}

\author{
C Perotti ${ }^{1,2}$, A Casas ${ }^{1,2}$, H Fukuda', P Sacca' and A Batlle*,1 \\ 'Centro de Investigaciones sobre Porfirinas y Porfirias (CIPYP), CONICET and Department of Biochemistry, School of Sciences, University of Buenos Aires, \\ Argentine
}

In recent years, 5-aminolevulinic acid-mediated photodynamic therapy (ALA-PDT) has become one of the most promising fields in photodynamic therapy research. ALA is the pro-drug of the photosensitiser Protoporphyrin IX (PpIX). After ALA administration, cells generate PpIX through the haem biosynthetic pathway. The main advantage of PpIX relative to other photosensitisers is the short half life of its photosensitising effects, which do not last longer than 48 h (Kennedy et al, 1990; Fukuda et al, 1992). Besides, ALA-induced porphyrin fluorescence may also assist in the early detection of some malignancies (Kriegmair et al, 1996).

Different approaches are currently under investigation to enhance ALA penetration, such as the application of ALA in various vehicles and the development of new synthetic molecules derived from ALA. Lipophilic derivatives of ALA were expected to have better diffusing properties, and after conversion into the parent ALA by enzymatic hydrolysis, to give a higher PpIX formation rate.

Photodynamic detection and PDT of bladder carcinoma was improved by the use of ALA esters (Marti et al, 1999; Lange et al, 1999). However, in spite of the success of ALA esters on increasing ALA cell membrane permeation (Kloek and Beijersbergen van Henegouwen, 1996; Kloek et al, 1998; Gaullier et al, 1997; Berger et al, 2000; Uehlinger et al, 2000; Casas et al, 2001a), the use of these compounds for the treatment of skin cancer is still a matter of discussion, due to the fact that they appear to diffuse slowly across the stratum corneum (Casas and Batlle, 2002).

Regarding the systemic administration of ALA and its esterified derivatives, there is some data concerning i.v. and oral administration of ALA (Loh et al, 1993; Gil et al, 1999), but to the best of our

*Correspondence: Professor Dr A Batlle; Viamonte I88I IOA, I056 Buenos Aires, Argentina; E-mail: batlle@mail.retina.ar

${ }^{2}$ The first two authors contributed equally to the work.

Received 18 March 2002; revised 13 June 2002; accepted 23 July 2002 knowledge there is as yet no published data regarding the systemic administration of He-ALA. The aim of this study was, therefore, to study the effect of the systemic administration of He-ALA on porphyrin tissue synthesis as compared to ALA.

\section{MATERIALS AND METHODS}

\section{Animals}

Male BALB/c mice, 12-weeks-old, weighing 20-25 g were used. They were provided with food (Purina 3, Molinos Río de la Plata) and water ad libitum. A suspension of $1.65 \times 10^{5}$ cells of the LM2 cell line (Galli et al, 2000) derived from the murine mammary adenocarcinoma M2 (Instituto Roffo, Buenos Aires) was subcutaneously injected into male $\mathrm{BALB} / \mathrm{c}$ mice. Experiments were performed approximately at day 20 after implantation. Tumours of the same uniform size were employed $(1 \mathrm{~cm}$ diameter $)$. Animals received human care and were treated in accordance with guidelines established by the Animal Care and Use Committee of the Argentine Association of Specialists in Laboratory Animals (AADEALC), in full accord with the UK Guidelines for the Welfare of Animals in Experimental Neoplasia (UKCCCR, 1988).

\section{Drugs}

ALA was purchased from SIGMA Chem Co., St. Louis, MO, USA. ALA hexyl-ester (He-ALA) was synthesised according to the method previously described by Casas et al (1999). All other chemicals were of analytical grade.

\section{ALA administration}

The hydrochloric acid salts of ALA and He-ALA were dissolved in saline in a final volume of $0.15 \mathrm{ml}$ immediately before intraperitoneal (i.p.) injection and in $0.05 \mathrm{ml}$ before intravenous (i.v.) injection. 


\section{Tissue porphyrin extraction}

At the indicated times after ALA or He-ALA administration, animals were sacrificed. Before killing, mice were injected with heparin $(0.15 \mathrm{ml}, 1000 \mathrm{UI})$ and after sacrifice, they were perfused with $200 \mathrm{ml}$ of sterile saline. The tissue samples were homogenised in a $4: 1$ solution of ethyl acetate:glacial acetic acid mixture. The mixtures were centrifuged for $30 \mathrm{~min}$ at $3000 \mathrm{~g}$, and the supernatants were treated with an equal volume of $5 \% \mathrm{HCl}$. Extraction with $\mathrm{HCl}$ was repeated until there was no detectable fluorescence in the organic layer. The aqueous fraction was used for the determination of porphyrins. For fluorometric determination, a Shimadzu RF-510 spectrofluorometer was used, with an emission wavelength of $604 \mathrm{~nm}$ and an excitation wavelength of $406 \mathrm{~nm}$, employing PpIX as a reference standard.

\section{ALA and He-ALA determination in brain}

ALA was determined by a modification of the Mauzerall and Granick (1956) method. Five minutes after ALA or He-ALA injection, mice were sacrificed and the brain was rinsed carefully. The tissue was then homogenised in $50 \mathrm{~mm}$ Tris $\mathrm{HCl}$ buffer $\mathrm{pH} 7.4$ and centrifuged at $3000 \mathrm{~g}$. The supernatant was condensed with acetylacetone at $100^{\circ} \mathrm{C}$ and then centrifuged to precipitate proteins. The ALA or He-ALA content in the resulting supernatant was quantified at $555 \mathrm{~nm}$ after addition of the Ehrlich reagent. The nanomoles of ALA and He-ALA per gram of tissue were calculated employing a calibration curve of ALA and He-ALA.

\section{Organ tissue cultures}

The explant tissue culture system developed by Polo et al (1988) has been used. Explants were floated in Petri dishes in serum-free minimal essential Eagle's medium (MEM), supplemented with $2 \mathrm{mM}$ L-glutamine and gentamycin $\left(40 \mu \mathrm{g} \mathrm{ml}^{-1}\right)$ and incubated at $37^{\circ} \mathrm{C}$ in presence of $0.6 \mathrm{~mm}$ ALA or He-ALA for $3 \mathrm{~h}$. After ALA or He-ALA exposure, explants of $50 \mathrm{mg}$ were homogenised in a 4:1 solution of ethyl acetate-glacial acetic acid mixture and porphyrins extracted and quantified as described above. Optimal conditions for incubations and explant sizes were as determined in a previous work (Fukuda et al, 1989).

\section{Statistical analysis}

The unpaired $t$-test was used to establish the significance of differences between groups. Differences were considered statistically significant when $P<0.05$. Three mice per group were employed. In vitro experiments were performed three times and run in duplicate.

\section{RESULTS}

Dose course of porphyrin synthesis after ALA or He-ALA administration via i.p.

Figure 1 shows porphyrin synthesis in tumour, normal skin and skin overlaying the tumour (SOT) after the i.p. administration of increasing doses of ALA or He-ALA. In all three tissues, ALA yielded higher levels of porphyrin synthesis than He-ALA.

In tumour tissue $7.5 \mathrm{mg}$ of ALA induced a plateau of $5.23 \pm 0.62 \mu \mathrm{g}$ porphyrin $\mathrm{g}^{-1}$ tissue, whereas He-ALA produced only a slight increase of porphyrins in a dose dependant way, reaching a maximal accumulation of $1.68 \pm 0.18 \mu \mathrm{g} \mathrm{g}^{-1}$ tissue at $10 \mathrm{mg}$. He-ALA doses higher than $10 \mathrm{mg}$ are lethal to animals, while ALA doses higher than $30 \mathrm{mg}$ lead to a diminished porphyr-

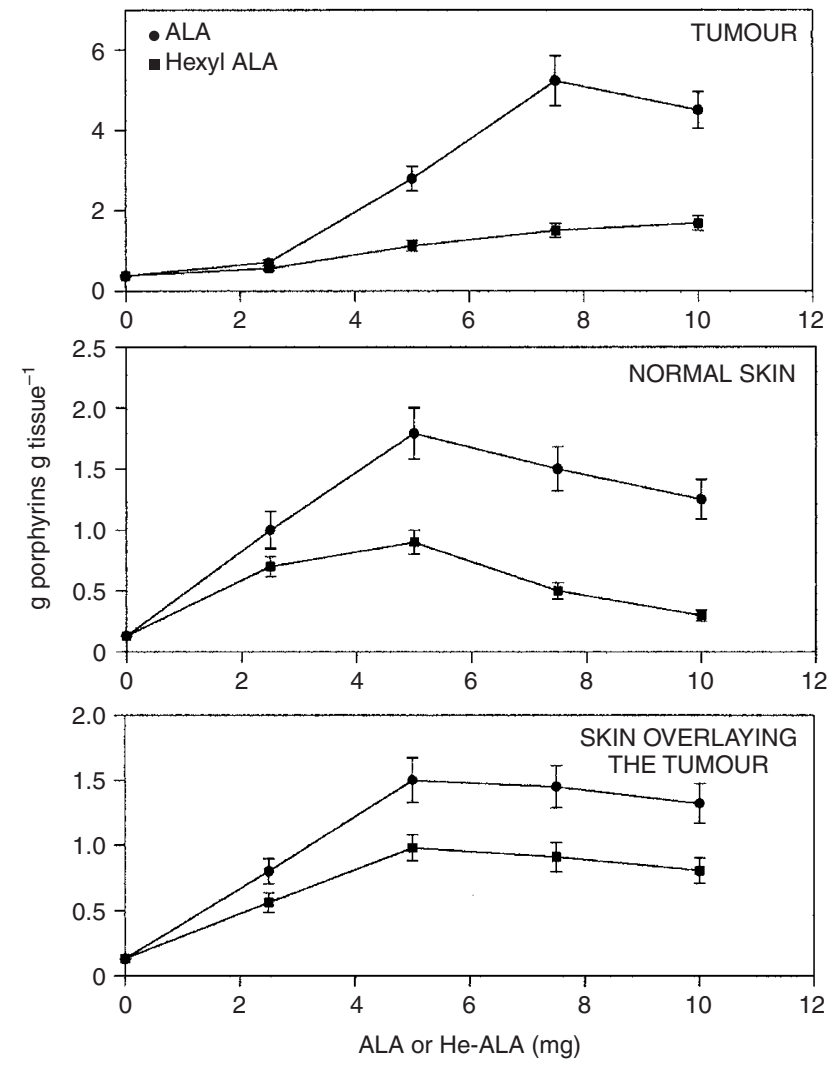

Figure I Porphyrin accumulation in tumour, skin and skin overlying the tumour after i.p. administration of increasing ALA or He-ALA doses. Different amounts of ALA or He-ALA were injected i.p. to mice. Three hours later, tissues were excised and porphyrins extracted as detailed in Materials and Methods. Each data point represents the average of three determinations. Error bars show standard deviations.

in synthesis and, at this dose, the mice autopsy reveled peritoneal thrombus formation.

In normal skin both ALA and He-ALA induced maximal accumulation of porphyrins at a concentration of $5 \mathrm{mg}$. A similar pattern was observed in the skin overlaying the tumour (SOT) for both compounds reaching plateaux also at $5 \mathrm{mg}$.

Figure 2 shows liver, kidney and brain porphyrin synthesis after the i.p. administration of ALA or He-ALA. In liver a plateau was observed with $5 \mathrm{mg}$ ALA. A dose dependent increase in porphyrin synthesis was observed with He-ALA, reaching a maximum at $10 \mathrm{mg}$. In kidney the administration of $7.5 \mathrm{mg}$ ALA induced a maximum amount of porphyrins, while He-ALA produced a slight peak at $5 \mathrm{mg}$.

The brain was the only tissue where porphyrins induced from He-ALA were higher when compared with ALA. A plateau of $1.47 \pm 0.12 \mu \mathrm{g}$ porphyrins $\mathrm{g}^{-1}$ was found with $5 \mathrm{mg}$ of He-ALA, surpassing 50 times basal porphyrin values. Meanwhile, ALA administration reached a plateau of $0.48 \pm 0.02 \mu \mathrm{g} \mathrm{g}^{-1}$, only 15 times ground levels.

Time course of porphyrin synthesis after ALA or He-ALA administration via i.p.

Figure 3 shows porphyrin accumulation for tumour, normal skin and SOT as a function of time after $5 \mathrm{mg}$ of ALA or He-ALA administration via i.p. In these tissues, independently of time, porphyrin accumulation was higher from ALA. In tumour and SOT both ALA and He-ALA induced a peak in porphyrin synthesis 

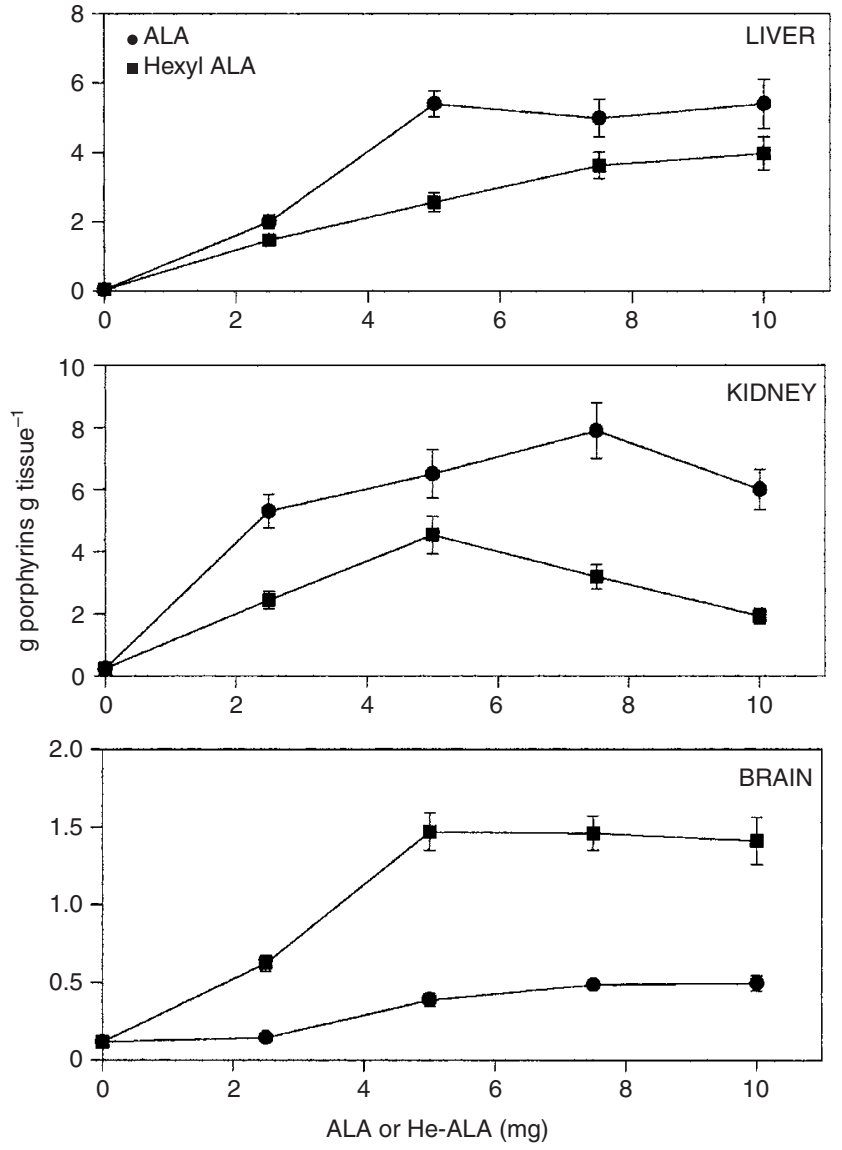

Figure 2 Porphyrin accumulation in liver, kidney and brain after i.p. administration of increasing ALA or He-ALA doses. Different amounts of ALA or He-ALA were injected i.p. to mice. Three hours later, tissues were excised and porphyrins extracted as detailed in Materials and Methods. Each data point represents the average of three determinations. Error bars show standard deviations.

between 3 and $5 \mathrm{~h}$. In normal skin ALA produced a peak at $3 \mathrm{~h}$ while the peak from He-ALA was at $5 \mathrm{~h}$.

Figure 4 shows porphyrin synthesis in liver, kidney and brain after ALA or He-ALA administration via i.p. In liver, ALA induced a peak at $3 \mathrm{~h}$, and He-ALA, a shoulder between 3 and $8 \mathrm{~h}$ and then a decrease in porphyrin synthesis towards basal levels at $24 \mathrm{~h}$ after administration. In kidney ALA induced a peak at $3 \mathrm{~h}$ and He-ALA a broad peak between 1 and $4 \mathrm{~h}$.

In brain He-ALA produced a maximal porphyrin accumulation of $2.98 \pm 0.27 \mu \mathrm{g} \mathrm{g}^{-1}$ at $5 \mathrm{~h}$ after administration, while ALA induced a maximum of $0.27 \pm 0.03 \mu \mathrm{g} \mathrm{g}^{-1}$ at $4 \mathrm{~h}$. In both cases values return to basal levels $24 \mathrm{~h}$ after administration.

Heart, lung, gut, spleen, bladder and ear tissues showed, in general, a porphyrin accumulation from ALA twice higher than that obtained from He-ALA (data not shown).

\section{Comparison of porphyrin tissue profiles between ALA and He-ALA injected via i.p. and i.v.}

The profiles of porphyrin accumulation in tumour, skin, SOT, liver, kidney, brain, heart, lung, gut, spleen, bladder and ear after administration of different doses of ALA and He-ALA i.p. and i.v. showed that there were no significant differences between i.p. and i.v. administration for most tissues, independently on the pro-drug used (data not shown).
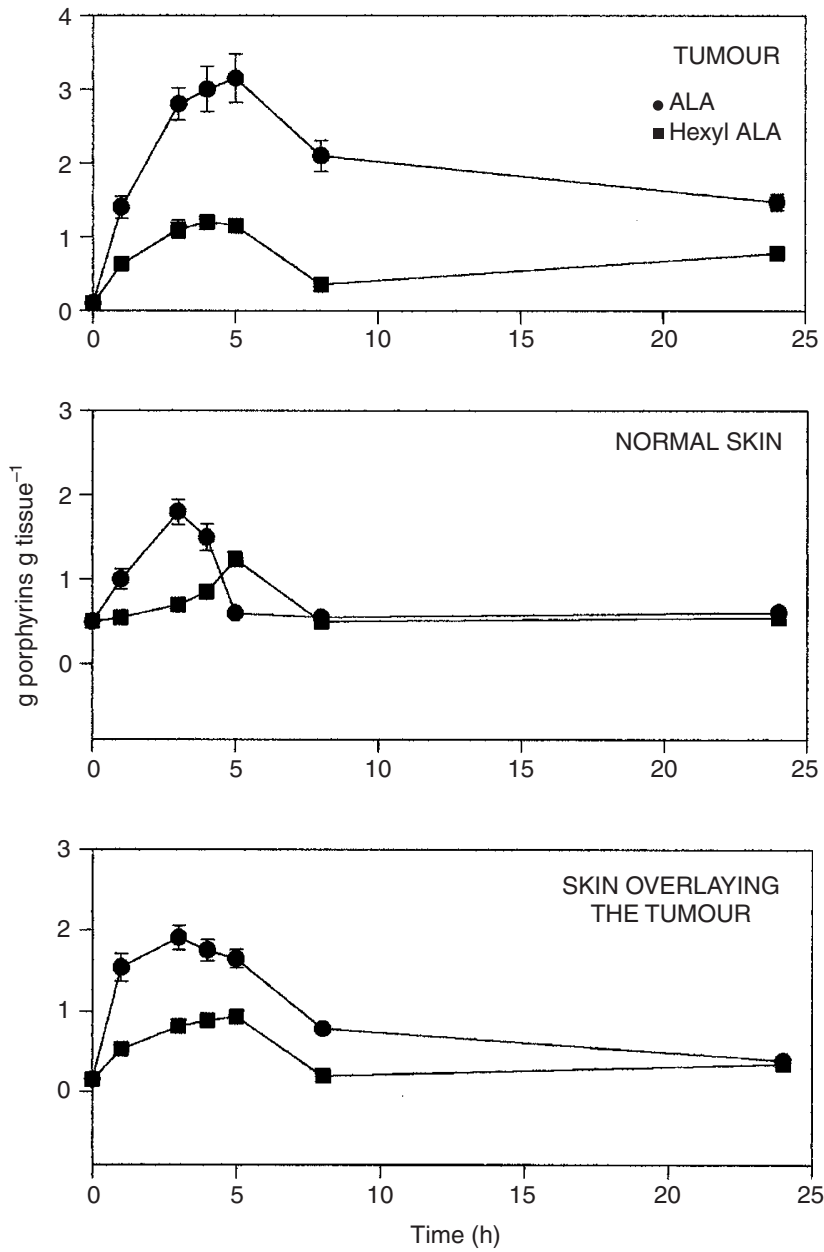

Figure 3 Porphyrin accumulation in tumour, skin and skin overlying the tumour different times after i.p. administration of ALA or He-ALA. 5 mg of of ALA or He-ALA were i.p. injected to mice. At different times, tissues were excised and porphyrins extracted as detailed in Materials and Methods. Each data point represents the average of three determinations. Error bars show standard deviations.

\section{Porphyrin synthesis in tissue explants from ALA and He-ALA as an estimation of esterase activities}

To determine if the differences on porphyrin accumulation among tissues were due either to ALA/He-ALA uptake and distribution or to differential tissue esterase activities, we performed organ cultures of the different tissues, exposed to either ALA or HeALA (Table 1).

We ran tissue explant cultures of tumour, liver, kidney, SOT, normal skin, spleen, lung, gut, bladder, brain and heart. We found that in all these tissues, the amount of porphyrins formed from He-ALA were similar to those obtained from equimolar ALA concentrations, and 10-15 times above basal values.

\section{ALA and He-ALA accumulation in brain after i.p. administration}

Equimolar concentrations of ALA and He-ALA (10 and $15 \mathrm{mg}$ respectively) were injected i.p. to mice. Due to the high toxicity observed for He-ALA leading to rapid death, we sacrificed the animals 5 min after injection. We observed (Table 2) that 6.7 times more He-ALA is accumulated in brain as compared with ALA. 


\section{DISCUSSION}

It has already been demonstrated (van den Akker et al, 2000) that after topical application of He-ALA, the stratum corneum of the skin acts as a barrier impairing its penetration through the skin. It has also been observed that topical use of He-ALA restricts porphyrin accumulation to the site of application (Casas et al, 2001b; Moan et al, 2001), but the same intensity of PpIX fluorescence using lower concentrations of ALA esters compared to ALA was obtained in the tissue layers of normal rat colon (Endlicher et $a l, 2001)$. On the other hand, employing cell lines of different
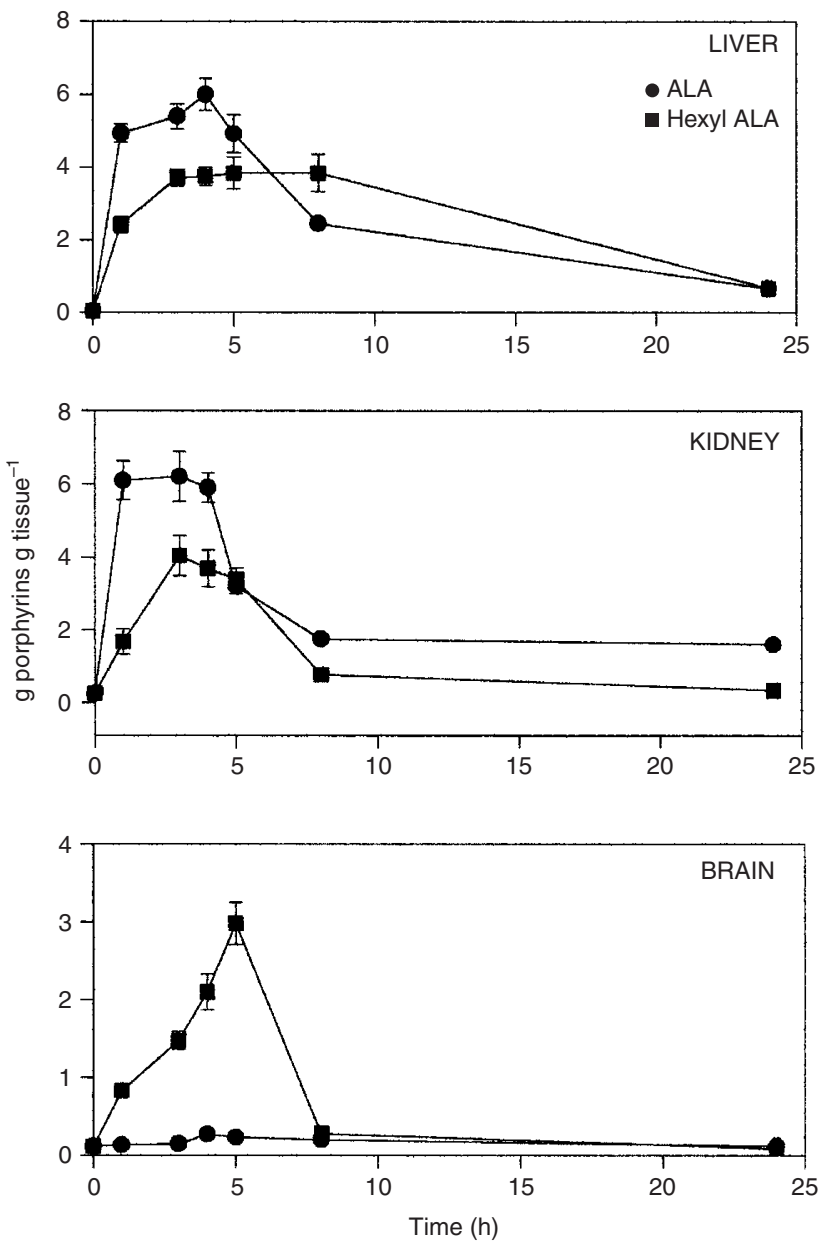

Figure 4 Porphyrin accumulation in liver, kidney and brain at different times after i.p. administration of ALA or He-ALA. $5 \mathrm{mg}$ of of ALA or He-ALA were i.p. injected to mice. At different times, tissues were excised and porphyrins extracted as detailed in Materials and Methods. Each data point represents the average of three determinations. Error bars show standard deviations. origins such as lung, bladder, glia, breast, lymphoma, leukemia, pancreas and colon among others (Luksiene et al, 2001; Casas and Batlle, 2002) porphyrin formation from He-ALA was not impaired, on the contrary it was highly increased by esterification of the ALA molecule.

In this work we have found that porphyrin synthesis from $\mathrm{He}$ ALA is lower than that from ALA in most tissues, and this does not depend on the dose and time after administration of either drug nor on the method of systemic administration (i.v. or i.p.) utilised.

Employing explant organ culture systems, this study has demonstrated, that porphyrin synthesis from He-ALA is equal to porphyrin synthesis from ALA in all tissues. The fact that tissue esterase was equally active in all tissues analysed, indicates that the ester cleavage is not the limiting step on porphyrin synthesis from He-ALA. This also shows that the distribution of either He-ALA, or porphyrins formed from He-ALA, is the reason why porphyrin accumulation is lower when compared with ALA.

On all these grounds, we hypothesise that on the passage of HeALA from the bloodstream to the tissues, the molecule is retained by vascular structures. The only tissue that accumulates a higher amount of porphyrins from He-ALA is the brain. The zwitterionic structure of aminoacids normally makes the penetration of the lipophilic blood-brain barrier difficult (Krogsgaard-Larsen et al, 2000), consequently, it is expected that the use of more lipophilic derivatives of ALA would favour their passage into the brain.

The structure of the blood-brain barrier allows lipophilic molecules such as He-ALA to extravasate and reach the brain, whereas the rest of the capillars retains the molecule. The role of lipophilicity has long been recognised as being important in central nervous system (CNS) penetration by chemicals. Measuring the apparent partition coefficients of the ALA esters between octanol and water (P), it has been demonstrated that the most potent compounds acting on the CNS have a $\log P$ value of $2 \pm 0.5$ (Hansch et al, 1987). On the other hand, Uehlinger et al (2000) determined that the $\log P$ value for He-ALA was 1.8 , whereas $\log P$ for ALA was -1.5 .

Besides having higher lipophilicity, the blood-brain barrier has specific transport systems and carrier proteins (Gloor et al, 2001). Although He-ALA transport has not yet been studied in neurons or glial cells, in other cell systems ALA and He-ALA seem to be taken up by distinct mechanisms (Casas and Batlle, 2002; Bermúdez Moretti et al, 2002). This may be the reason why delivery of HeALA to the brain is different from other tissues.

Table 2 ALA and He-ALA levels in brain

\begin{tabular}{lc}
\hline & nmol ALA or He-ALA g brain $^{-1}$ \\
\hline Control & $17 \pm 3$ \\
ALA & $60 \pm 5$ \\
He-ALA & $404 \pm 10$ \\
\hline
\end{tabular}

$15 \mathrm{mg}$ of $\mathrm{He}$-ALA and $10 \mathrm{mg}$ of ALA were administered i.p. to mice. Five minutes later, mice were sacrificed and ALA and He-ALA were determined as described in Materials and Methods. Controls correspond to basal ALA levels of non-treated mice.

Table I Porphyrin synthesis from tissue explants incubated with ALA or He- ALA

\begin{tabular}{|c|c|c|c|c|c|c|c|c|c|c|c|}
\hline Tissue & Tumour & Liver & Spleen & Kidney & SOT & Normal skin & Lung & Gut & Bladder & Brain & Heart \\
\hline
\end{tabular}

Explants were incubated $3 \mathrm{~h}$ with $0.6 \mathrm{mM}$ of ALA or He-ALA, porphyrins were extracted and determined as described in Materials and Methods. Controls correspond to tissues basal porphyrin levels. 
The amount of ALA/He-ALA accumulated in brain 5 min after He-ALA injection is almost seven times higher than the amount found after ALA treatment. This correlates well with the seven-fold increase in brain porphyrin levels from He-ALA as compared with ALA. Since we cannot differentiate ALA from He-ALA with our method of determination, we cannot determine if He-ALA leads to a rapid and sudden death at high concentrations due to a toxicity induced per se or if it is rapidly cleaved by brain esterases to release ALA and hexanol, both of them very harmful compounds at high concentrations.

The amount of ALA/He-ALA that we found in brain is equal to $0.5 \mu \mathrm{M}$ after He-ALA injection and $0.073 \mu \mathrm{M}$ after ALA injection. The amount of ALA present in CSF of porphyric patients during acute attacks ranges widely between 0.027 and $21 \mu \mathrm{M}$ (Sweeney et al, 1970; Percy and Shanley, 1979; Gorchein and Webber, 1987). However, we cannot predict from these and our values whether or not He-ALA resembles the effects of an acute attack.

In conclusion, we propose that the clinical use of a low dose of He-ALA administered systemically will probably contribute to the

\section{REFERENCES}

Berger Y, Greppi A, Siri O, Neier R, Jullierat-Jeanneret L (2000) Ethylene glycol and amino acid derivatives of 5-aminolevulinic acid as new photosensitizing precursors of Protoporphyrin IX. J Med Chem 43: 4738-4746

Bermúdez Moretti M, Correa García S, Perotti C, Batlle A, Casas A (2002) $\delta$ aminolevulinic acid transport in mammary adenocarcinoma cells is mediated by beta transporters. Br J Cancer (in press)

Casas A, Batlle A, Butler A, Robertson D, Brown E, MacRobert A, Riley P (1999) Comparative effect of ALA derivatives on Protoporphyrin IX production in human and rat skin organ cultures. $\mathrm{Br} J$ Cancer 80: $1525-1532$

Casas A, Fukuda H, Di Venosa G, Batlle A (2001a) Photosensitisation and mechanism of cytotoxicity induced by the use of ALA derivatives in photodynamic therapy. $\mathrm{Br} J$ Cancer 85: 279-284

Casas A, Perotti C, Fukuda H, Rogers L, Butler A, Batlle A (2001b) HexylALA induces selective porphyrin synthesis in chemically induced skin tumours confined to the site of application: implications in cutaneous photosensitisation. Br J Cancer 85: $1740-1800$

Casas A, Batlle A (2002) Rational design of 5-aminolevulinic acid derivatives aimed at improving Photodynamic Therapy. Curr Med Chem Anti-Cancer Agents 2: $465-475$

Endlicher E, Rümmele P, Hausmann F, Krief R, Knüchel R, Rath HC, Schölmerich H, Messmann H (2001) Protoporphyrin IX distribution following local application of 5-aminolevulinic acid and its esterified derivatives in the tissue layers of the normal rat colon. Br J Cancer 85: 1572-1576

Fukuda H, Paredes S, Batlle A (1989) Tumor-localizing properties of porphyrins. in vitro studies using the porphyrin precursor, aminoevulinic acid, in free and liposome encapsulated forms. Drug Des Deliv 6: 133-139

Fukuda H, Paredes S, Batlle A (1992) Tumour-localizing properties of porphyrins. in vivo studies using free and liposome encapsulated aminolevulinic acid. Comp Biochem Physiol 102B: 433-436

Galli S, Colombo L, Vanzuli S, Daroqui M, Vidal M, Jasnis A, Lustig E, Eiján A (2000) Characterization of a fibroblastoid mammary carcinoma cell line (LM2) originated from a mouse adenocarcinoma. Int J Oncol 17: 12591265

Gaullier J, Berg K, Peng Q, Anholt H, Selbo P, Ma L, Moan J (1997) Use of 5 aminolevulinic acid esters to improve photodynamic therapy on cells in culture. Cancer Res 57: $1481-1486$

Gil M, Woszczynski M, Regula J, MacRobert A, Butruk E, Bown S (1999) Topical versus systemic 5 -aminolevulinic acid administration for photodynamic therapy of the colon in B10.RBP mice. J Biomedical Optics 4: $286-$ 201

Gloor S, Wachtel M, Bolliger M, Ishihara H, Landmann R, Frei K (2001) Molecular and cellular permeability control at the blood-brain barrier. Brain Res Rev 36: 258-264

Gorchein A, Webber R (1987) 5-aminolevulinic acid in plasma, cerebrospinal fluid, saliva and erythrocytes: studies in normal, uraemic and porphyric subjects. Clin Sci 72: 103-112 delimitation and treatment of brain tumors, although much care should be taken regarding side effects and possible toxicity driven by resulting ALA, He-ALA or its hydrolysis product hexanol.

\section{ACKNOWLEDGEMENTS}

This research was supported by grants from the Argentine National Research Council (CONICET) (PIP 4108/96 and 105508/99-00), the Science and Technology Argentine Agency (STAA) (PICT 0500000-01861 and the Association for International Cancer Research (AICR) from UK. We wish to thank Mrs V Castillo for her skilful technical assistance. A Batlle and $\mathrm{H}$ Fukuda hold the posts of Superior and Associate Researchers at the Scientific Researcher Career at CONICET. A Casas is a CONICET postdoctoral fellow. C Perotti is a Carrillo-Oñativia fellow, Ministerio de Salud Pública and $\mathrm{P}$ Sacca is Assistant Researcher at the Scientific Research Support Career at the CONICET.
Hansch C, Bjorkroth J, Leo A (1987) Hydrophobicity and central nervous system agents: on the principle of minimal hydrophobicity in drug design. J Pharm Sci 76: 663-687

Kennedy J, Pottier R, Pross D (1990) Photodynamic therapy with endogenous protoporphyrin IX: basic principles and basic clinical experience. $J$ Photochem Photobiol B: Biol 6: 143-148

Kloek J, Akkermans W, Beijersbergen van Henegouwen G (1998) Derivatives of 5-Aminolevulinic acid for Photodynamic therapy: enzymatic conversion into protoporphyrin. Photochem Photobiol 67: 150-154

Kloek J, Beijersbergen van Henegouwen G (1996) Prodrugs of 5-aminolevulinic acid for photodynamic therapy. Photochem Photobiol 64: 994-1000

Kriegmair M, Baumgartner R, Knuechel R, Stepp H, Hofstädter F, Hofstetter A (1996) Detection of early bladder cancer by 5 -aminolevulinic acid induced porphyrin fluorescence. J Urology 155: 105-110

Krogsgaard-Larsen P, Frolund B, Frydenvang K (2000) GABA uptake inhibitors, design, molecular pharmacology and therapeutic aspects. Curr Pharm Design 6: $1193-1209$

Lange N, Jichinlinski P, Zellweger M, Forrer M, Marti A, Guillou L, Kuchera P, Wagnieres G, van den Bergh H (1999) Photodetection of early human bladder cancer based on the fluorescence of 5-aminolevulinic acid hexylester-induced protoporhyrin IX: a pilot study. Br J Cancer 80: 185-193

Loh C, MacRobert A, Bedwell J, Krasner N, Bown S (1993) Oral versus intravenous administration of 5 -aminolevulinic acid for photodynamic therapy. Br J Cancer 68: $41-51$

Luksiene Z, Eggen I, Moan J, Nesland JM, Peng Q (2001) Evaluation of protoporphyrin IX production, phototoxicity and cell death pathway induced by hexylester of 5 -aminolevulinic acid in Reh and HPB-ALL cells. Cancer Letters 169: $33-39$

Marti A, Lange N, van den Bergh H, Sedmera D, Jichlinski P, Kucera P (1999) Optimisation of the formation and distribution of protoporphyrin IX in the urothelium: an in vitro approach. J Urol 162: 546-552

Mauzerall D, Granick S (1956) The occurrence and determination of 5aminolevulinic acid and porphobilinogen in urine. J Biol Chem 219: $435-446$

Moan J, Ma L, Iani V (2001) On the pharmacokinetics of topically applied 5aminolevulinic acid and two of its esters. Int J Cancer 92: 139-143

Percy V, Shanley B (1979) Studies on haem biosynthesis in rat brain. J Neurochem 33: $1267-1274$

Polo C, Navone N, Afonso S, Vazquez E, Buzaleh A, Bianchi A, Schoua E, Batlle A (1988) Induction of porphyrin biosynthesis in tissue explants and the effect of anitimitotics. ATLA 16: $137-147$

Sweeney V, Pathak M, Asbury A (1970) Acute intermittent porphyria, increased ALA-synthetase activity during an acute attack. Brain 93: $369-380$ 
Uehlinger P, Zellweger M, Wagnieres G, Juillerat-Jeanneret L, van den Bergh $\mathrm{H}$, Lange $\mathrm{N}$ (2000) 5-aminolevulinic acid and its derivatives: physical chemical properties and protoporphyrin IX formation in cultured cells. $J$ Photochem Photobiol B:Biol 54: 72-80

UK-Coordinating Committee on Cancer Research (1988) UKCCCR Guidelines for the Welfare of Animals in Experimental Neoplasia. London: UKCCCR van den Akker J, Iani V, Star W, Sterenborg H, Moan JV (2000) Topical application of 5-aminolevulinic acid hexyl ester and 5-aminolevulinic to normal nude mouse skin: differences in Protoporphyrin IX fluorescence kinetics and the role of the stratum corneum. Photochem Photobiol 72: $681-689$ 